\title{
Análise da suscetibilidade à desertificação na bacia hidrográfica do rio pontal - Pernambuco - Brasil
}

\section{Susceptibility analysis of desertification in the basin of river headland - Pernambuco - Brazil}

\author{
Pedro dos Santos Ferreira ${ }^{1}$; Antonio Marcos dos Santos²; Johnny Mayron Santana Ferreira ${ }^{3}$; \\ Henrique dos Santos Ferreira ${ }^{3}$; Josiclêda Domiciano Galvício ${ }^{1}$
}

\begin{abstract}
Resumo
O atual modelo de desenvolvimento econômico adotado pela sociedade, baseado no consumo, tem chamado a atenção dos ambientalistas em função da forte pressão que o mesmo vem exercendo sobre os ambientes naturais. Esta pressão vem resultando em graves problemas de ordem socioambiental. Entre eles, a desertificação surge como o grande desafio a ser enfrentado. A desertificação é entendida como um processo de degradação das terras áridas, semiáridas e subúmidas secas, resultante de variações climáticas e atividades humanas. Nesse sentido, o objetivo deste artigo é analisar o grau de suscetibilidade à desertificação da bacia hidrográfica do rio Pontal. Para mapeamento da suscetibilidade à desertificação, foram cruzadas cartas com os atributos de uso e cobertura da terra, solos, declividade, potencial erosivo da chuva e índice de aridez. No geral a bacia apresentou baixa suscetibilidade à desertificação, sendo a retirada da cobertura vegetal a principal responsável pelo aparecimento de áreas de maior risco. Devido a grande importância econômica da bacia do Pontal, em função da expansão dos perímetros irrigados, propõe-se que outros estudos sejam desenvolvidos no sentido de encontrar alternativas viáveis para o combate à desertificação.
\end{abstract}

Palavras-chave: agricultura, desmatamento, erosão, geoprocessamento.

\begin{abstract}
The current economic development model adopted by society, based on consumption, has drawn the attention of environmentalists due to the strong pressure that it has exerted on natural environments. This pressure has resulted in serious problems of environmental order. Among them, desertification emerges as the major challenge to be faced. Desertification is understood as a process of degradation of arid, semi-arid, and dry sub-humid lands, resulting from climatic variations and from the impact of human activities. In this sense, the aim of this paper is to analyze the degree of susceptibility to desertification of the river basin of Pontal. For the mapping of susceptibility to desertification, we extrapolated georeferenced data such as land use and land cover, soils, slope, erosion potential of rain and aridity index. Overall the basin presented low susceptibility to desertification, and the removal of vegetation cover was identified as the main responsible for the appearance of high susceptibility areas. Due to the great economic importance of the Pontal basin, because of expansion of irrigated areas, this research proposes that further studies need to be developed in order to find viable alternatives to the desertification combat.
\end{abstract}

Keywords: agriculture, deforestation, erosion, geoprocessing.

Recibido el 03 de octubre de 2016, aceptado el 03 de mayo de 2017.

1 Programa de Pós Graduação em Desenvolvimento e Meio Ambiente (PRODEMA), Universidade Federal de Pernambuco, Brasil.

2 Grupo de Trabalho em Monitoramento Ambiental, Geotecnologia e Ensino (GTMAGEO), Universidade de Pernambuco, Rodovia BR 203, Km 2, s/n. Vila Eduardo. Petrolina. PE. Brasil. Email: geo_fisica@yahoo.com.br

3 Universidade Ferederal de Pernambuco, Brasil. 


\section{Introdução}

Oatual modelo de desenvolvimento econômico adotado pela sociedade, baseado no consumo segundo Santos (2006), é apontado por vários ambientalistas como o principal. responsável pela forte pressão que se verifica sobre os recursos naturais. Em decorrência do referido dinamismo, a sociedade do século XXI deparase com graves problemas de ordem ambiental, entre os quais, a desertificação figura como um dos grandes desafios que precisam ser enfrentados em face da ameaça à segurança alimentar. O fenômeno mencionado, segundo definição da United Nations Convention to Combat Desertification (UNCCD, 1994), é entendido como um processo de degradação das terras áridas, semiáridas e subúmidas secas, resultante de variações climáticas e das mais diversas e complexas atividades humanas (Sampaio, Sampaio, Vital, Araújo, \& Sampaio, 2003; D’Odorico, Bhattachan, Davis, Ravi, \& Runya, 2013, Santos \& Galvíncio, 2013).

No quadro atual, os processos de desertificação verificados em várias partes do mundo decorrem principalmente das rápidas mudanças no uso e na cobertura das terras, mau uso dos solos o que contribuiu para maior exposição dos solos, tornandoos mais vulneráveis aos agentes erosivos (Sampaio, 2009; Granados-Sánchez, Hernandez-García, Vázquez-Alarcon, \& Ruiz-Puga, 2013; Ge, Li, Luloff, Dong, \& Xiao, 2015). Geralmente o desmatamento, principalmente o extensivo, é realizado por meio de queimadas, prática que é apontada como grande responsável direta pelo empobrecimento dos nutrientes presentes nos solos. $\mathrm{O}$ processo pode também se encontrar associado ao manejo inadequado, sobrepastoreiro e utilização inadequada de sistemas de irrigação (Bezerra, Silva, Morais, \& Batista, 2011; Hänke, Börjeson, Hylander, \& Enfors-Kautsky, 2016).

Por outro lado, é importante salientar que os efeitos decorrentes do referido processo são sistemáticos e generalizados. Algumas alterações são verificadas também nos recursos hídricos, onde as mudanças no padrão de infiltração de água no solo e escoamento superficial das bacias hidrográficas contribuem diretamente para a redução da disponibilidade hídrica para múltiplos usos (Aquino, Oliveira, \& Sales, 2006). Somam-se ao exposto, as questões relacionadas à perda da biodiversidade animal e vegetal (Becerril-Pina, MastachiLoza, Sosa, Díaz-Delgado, \& Bâ, 2015).

Aspectos mais danosos recaem, principalmente, sobre a redução da fertilidade e capacidade de produção das terras, por se tratar, muitas vezes, de um quadro irreversível (Lingbeek, Higgins, Muir, Kattes, \& Schwertner, 2017). Sampaio et al. (2003) pontua que o declínio da produtividade deve refletir na renda dos trabalhadores ligados ao setor agropecuário, promovendo a defasagem de serviços como educação e saúde, acarretando na redução de importantes indicadores de desenvolvimento, como o Índice de Desenvolvimento Humano (IDH). Outro ponto a ser destacado é a possibilidade da intensificação dos processos de migração das populações rurais residentes nas áreas atingidas.

A desertificação é um processo que pode ser observado em várias partes do mundo (Wang \& Yan, 2016). No território mexicano, aproximadamente $34 \%$ das terras apresentam deterioração em decorrência da desertificação. As forças motrizes que impulsionam o processo decorrem das alterações no uso e cobertura da terra e pastoreio excessivo. Em escala de bacia hidrográfica, a combinação de fatores como o uso de sistemas de irrigação inadequados, menor potencial pluvial, exploração excessiva dos recursos e elevadas taxas de evapotranspiração anual, ajudam a explicar o avançado grau de degradação nessas áreas (Mercado-Mancera et al., 2011).

No semiárido africano, as terras biologicamente produtivas vêm sendo convertidas em desertos desde a década de 1960. Durante os anos de 1968 e 1974 os processos foram potencializados em decorrência da grande seca de assolou as áreas semiáridas da África. Diante 
da questão, houve uma mobilização que resultou em um esforço internacional para conter a expansão das áreas desertificadas.

No do Oriente Médio, a desertificação é uma questão intensamente discutida, visto que se encontra entre os principais problemas de ordem ambiental que assola a região. De acordo com Abahussain, Abdu, Al-Zubari, EL-Deen, \& Abdul-Raheem (2002), fatores naturais como a recorrência de secas de longos períodos e erosão eólica, atrelados a práticas antrópicas como desmatamento, sobrepastoreio, uso inadequado dos recursos hídricos e modelos agrícolas ambientalmente ineficientes são apontados como determinantes para a construção do quadro observado.

No Brasil, as regiões semiáridas necessitam de uma maior atenção, principalmente as áreas onde o problema da desertificação é mais acentuado. Landim, Silva, \& Almeida (2011) utilizaram imagens de satélite para investigar a influência dos fatores naturais e antrópicos sobre o processe de degradação dos solos no núcleo de desertificação de Irauçuba, estado do Ceará - Brasil. Os resultados obtidos por meio de índices de vegetação indicaram diminuição das áreas de vegetação densa e aumento da esparsa, assim como redução dos corpos hídricos. Fatores que, segundo o autor, parecem ter sido determinantes para o quadro ambiental observado na região.

Em Pernambuco, as áreas suscetíveis à desertificação representam $90 \%$ de todo território. Configuração que se deve incialmente, aos fatores climáticos, que somados intervenções antrópicas desencadeiam todo o processo. Um bom exemplo do exposto é o núcleo de desertificação de Cabrobó, que engloba os municípios de Belém do São Francisco, Itacuruba, Carnaubeira da Penha, Floresta e Cabrobó SECTMA (2009).

Vale ressaltar que as áreas que apresentam maior risco de degradação são justamente as que sofreram algum tipo de modificação nas suas configurações naturais. De acordo com Ferreira, Gómes, Santos, Morais, Miranda, Ferreira, \& Galvíncio (2014), os quais mapearam as áreas suscetíveis à desertificação na bacia hidrográfica do rio Pajeú, estado de Pernambuco, Brasil, as áreas utilizadas para o desenvolvimento de práticas agrícolas e pecuárias, concentradas principalmente na microrregião do Sertão do Pajeú, apresentaram Alta suscetibilidade à desertificação. É importante salientar que, neste caso, o fator socioeconômico é muito importante, já que a maior parte das áreas que compõem a microrregião do Sertão do Pajeú é utilizada para o desenvolvimento da agricultura familiar, sistema de produção mais rústico e que dispõe de menos recursos e conhecimento dos agricultores.

Existe na região semiárida do Nordeste um conjunto de fatores naturais $\mathrm{e}$ socioeconômicos que contribuem para a construção de um quadro ambiental insustentável no que tange a exploração dos recursos naturais. Por outro lado, as ações de combate à desertificação, por meio do desenvolvimento de políticas públicas ainda esbarram na falta de informações cruciais para enfrentamento da questão. Nesse sentido, o objetivo central do presente estudo consiste em mapear e analisar o grau de suscetibilidade à desertificação da bacia hidrográfica do rio Pontal, estado de Pernambuco.

\section{Material e métodos}

\section{Área de estudo}

A bacia hidrográfica do rio Pontal está localizada no estremo oeste do estado de Pernambuco, conforme figura 1. A unidade ambiental possui área de $6.015,33 \mathrm{~km}^{2}$, ocupada pelos municípios de Petrolina, Lagoa Grande, Dormentes e Afrânio. Ressalta-se que apenas Afrânio encontra-se totalmente inserido na bacia do rio Pontal. De maneira geral, as bases econômicas desses municípios encontram-se atreladas ao setor agrícola, com destaque para o polo fruticultor de Petrolina, onde a maior parte produção é voltada para a exportação (IBGE, 2010). 


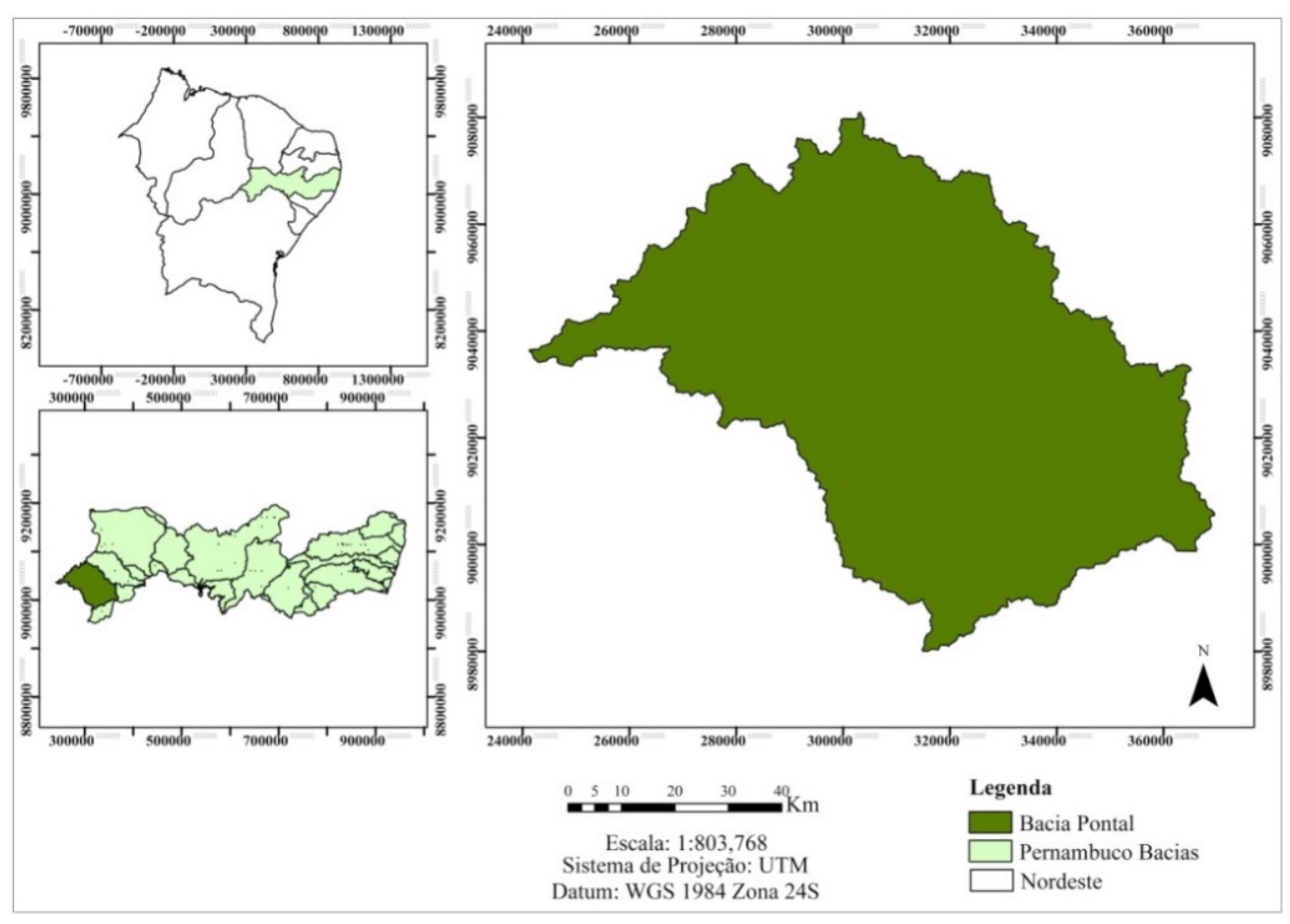

Figura 1. Localização da bacia hidrográfica do rio Pontal. Fuente: Elaboração própria (2016)

Figure 1. Location of River Basin Pontal. Source: Own elaboration (2016)

O clima predominante na região é o tropical semiárido, conforme classificação de Köppen. As chuvas são bastante escassas e concentram-se entre os meses de dezembro a abril, sob influência de sistemas atmosféricos dinâmicos, entre os quais, destaca-se a Zona de Convergência Intertropical (ZCIT), a penetração de sistemas oriundos de latitudes médias austrais, Vórtices Ciclônicos de Altos Níveis (VCAN) e a Oscilação de MaddenJulian (Lucena, Gomes Filho, \& Servain, 2011).

\section{Procedimentos metodológicos}

A carta representando os tipos de solos da bacia foi utilizada para representar o grau de fragilidade à erosão de cada classe de solo conforme metodologia proposta por Crepani, Medeiros, Palmeira, \& Silva, (2008) e Ferreira et al. (2014). A base de dados empregada na confecção da carta de solos foi adquirida junto ao Zoneamento Agroecológico do Estado de Pernambuco (ZAPE) no formato vetorial.
A carta referente à declividade da área de estudo, a qual representa a variável geomorfológica, foi produzida a partir do processamento das imagens de radar Shuttle Radar Topographic Mission (SRTM), disponibilizada por Miranda (2005).

Já o potencial erosivo das chuvas foi obtido a partir das equações 1 e 2, propostas por Bertoni \& Lombardi (1999). Os dados de precipitação pluviométrica correspondem à média histórica (1961 a 1990) de três postos pluviométricos dentro e próximos à bacia hidrográfica estudada. Estes dados foram adquiridos junto ao Laboratório de Meteorologia do Estado de Pernambuco (LAMEPE).

$$
E I=67,355 *\left(\frac{r^{2}}{P}\right)^{0,85}
$$

Equação 1

Em que: $I E$ é a média mensal do índice de erosão $\left(\mathrm{MJ} \mathrm{mm} \mathrm{ha}^{-1}\right), r$ é a precipitação 
média mensal dada em milímetros e $P$ é a média anual da precipitação $(\mathrm{mm})$. Os índices de erosão mensal (IE) foram posteriormente somados no sentido de obter o índice de erosividade ( $R$, MJ $\mathrm{mm}$ ha $^{-1}$ ano $^{-1}$, Equação 2).

$$
R=\sum E I
$$

Equação 2

A carta de Suscetibilidade Climática à Desertificação (SCD) foi obtida com base no Índice de Aridez (IA - Equação 3), para o qual utilizou-se o balanço hídrico de Thornthwaite \& Mather (1955). Este índice é utilizado pela Convenção de Combate à Desertificação para identificação das áreas climaticamente suscetíveis ao desenvolvimento de processos de desertificação.

$$
I A=100 *\left(\frac{P}{E T o}\right)
$$

Equação 3

Em que: IA é o índice de aridez, $P$ é a precipitação pluviométrica média anual, ETo representa a evapotranspiração potencial (ETP), calculada a partir do método proposto por Thornthwaite \& Mather (1955).

A variável de uso e cobertura da terra representa os tipos de usos desenvolvidos na superfície, e é um importante parâmetro para avaliar o grau de contribuição da vegetação voltada para proteção dos solos. Para mapear a estrutura do uso e cobertura da bacia hidrográfica do rio Pontal foram utilizadas imagens orbitais do sensor Operational Land Imager (OLI), acoplado ao satélite Landsat 8, obtidas junto a U.S. Geological Survey (USGS). O produto possui resolução espacial, para as bandas multiespectrais, de 30 metros e resolução radiométrica de 16 bits. Para que toda área de estudo fosse devidamente representada, foram utilizadas duas cenas. A primeira corresponde órbita 217 , zona 66 , enquanto a segunda refere-se à órbita 218 , na zona 66. $\mathrm{O}$ imageamento é relativo à data de passagem do satélite na área, em 30 de abril de 2013, período considerado ideal devido à ausência de nuvens.
A classificação do mapeamento foi realizada com base no Índice de Vegetação por Diferença Normalizada (IVDN), descrito na Equação 4. Também se utilizou como base o banco de dados do Projeto de Conservação e Utilização Sustentável da Diversidade Biológica brasileira (PROBIO), assim como imagens presentes no banco de dados do Google Earth.

$$
N D V I=\left(\frac{N I R-R}{N I R+R}\right) \quad \text { Equação } 4
$$

Em que: NIR representa o a banda espectral correspondente ao Infravermelho próximo $(0,75 \mu \mathrm{m}-0,90$ $\mu \mathrm{m})$ e $\mathrm{R}$ representa a banda espectral correspondente ao Vermelho $(0,63 \mu \mathrm{m}$ $0,70 \mu \mathrm{m})$.

Após levantamento de dados e produção das cartas, as classes de cada atributo receberam notas (tabela 1), conforme proposta metodológica adotada para este estudo, as quais foram baseadas nos estudos de: Crepani et al. (2008), Santos \& Galvício (2013) e Ferreira et al. (2014). Em segunda, os atributos foram cruzados empregando as ferramentas de geoprocessamento para produção das cartas de Suscetibilidade a Erosão (SE) e Suscetibilidade à Desertificação (SD).

\section{Resultados e discussão}

\section{Estrutura do uso e cobertura da terra}

O mapeamento dos atributos de uso e cobertura da terra está exposto na figura 2 , a qual expõe quatro classes de uso e cobertura da terra. Dentre as categorias observadas, a Savana Estépica é a mais representativa, ocupando cerca de $73,8 \%$ da área de estudo. Esta categoria é bem adaptada à dupla estacionalidade climática do semiárido nordestino. Estre os mecanismos de defesa desenvolvidos pela vegetação está à liberação da folhagem durante o período seco, permitindo a planta minimizar o estresse luminoso e perda de água por evapotranspiração. 


\section{Tabela 1}

Resumo das Notas atribuídas às classes de cada atributo. Fonte: Elaboração própria, 2016. Adaptado de: Santos \& Galvíncio (2013) e Ferreira et al. (2014)

\section{Table 1}

Summary of notes assigned to the classes of each atribute. Source: Own elaboration, 2016, based on Santos \& Galvíncio (2013) and Ferreira et al. (2014)

\begin{tabular}{|c|c|c|c|c|c|c|c|}
\hline \multirow{3}{*}{$\begin{array}{l}\text { Grau de } \\
\text { suscetibilidade }\end{array}$} & \multirow{3}{*}{ Notas } & \multicolumn{6}{|c|}{ Classes e atributos ambientais } \\
\hline & & \multicolumn{2}{|c|}{ Geomorfológico } & \multicolumn{2}{|l|}{ Pedológico } & \multicolumn{2}{|c|}{ Índice de Aridez } \\
\hline & & $\begin{array}{l}\text { Declividade } \\
(\%)\end{array}$ & Relevo & Classes de solos & & Intervalos & $\begin{array}{l}\text { Tipologia } \\
\text { climática }\end{array}$ \\
\hline Muito baixa & 1 & $>3$ & Plano & $\begin{array}{l}\text { Latossolo } \\
\text { Amarelo e } \\
\text { Neossolos } \\
\text { Flúvicos }\end{array}$ & $\begin{array}{l}\text { Savana } \\
\text { Estépica } \\
\text { Florestada }\end{array}$ & $1-0,66$ & Subúmido \\
\hline Baixa & 2 & $3-8$ & $\begin{array}{l}\text { Suave } \\
\text { ondulado }\end{array}$ & Argissolos & --- & $0,65-0,50$ & $\begin{array}{l}\text { Subúmido } \\
\text { Seco }\end{array}$ \\
\hline Média & 3 & $8-20$ & $\begin{array}{l}\text { Moderadamente } \\
\text { ondulado a } \\
\text { Ondulado }\end{array}$ & $\begin{array}{l}\text { Planossolos e } \\
\text { Luvissolos }\end{array}$ & $\begin{array}{l}\text { Savana } \\
\text { Estépica } \\
\text { Arborizada } \\
\text { e Influência } \\
\text { Fluvial }\end{array}$ & $0,51-0,21$ & Semiárido \\
\hline Alta & 4 & $20-45$ & $\begin{array}{l}\text { Fortemente } \\
\text { ondulado }\end{array}$ & Cambissolos & $\begin{array}{l}\text { Savana } \\
\text { Estépica } \\
\text { Parque }\end{array}$ & -- & --- \\
\hline Muito Alta & 5 & $45-50$ & Montanhoso & $\begin{array}{l}\text { Neossolo } \\
\text { Regolítico, Neo. } \\
\text { Quartizarênico, } \\
\text { Neo. Litólico }\end{array}$ & Agropecuária & --- & --- \\
\hline
\end{tabular}

De maneira geral, a Savana Estépica pode ser dividida em dois subgrupos. O primeiro corresponde a Savana Estépica Florestada, ou Caatinga Arbustiva, que segundo Souza, Artigas, \& Lima (2015) comporta indivíduos de baixo porte com fisionomia arbustiva. Nesta classificação, forma paisagens com florestas bem adensadas. Quanto ao segundo grupo, estes são semelhantes ao primeiro, porém diferem principalmente no que se refere à disposição no espaço, já que na composição da paisagem observa-se certo espaçamento entre os indivíduos, formando algumas clareiras.
Este tipo de vegetação exerce um importante papel na proteção dos solos, tornando-os menos vulneráveis aos agentes erosivos. Os próprios mecanismos adaptativos da vegetação, como a perda de folhagem, auxiliam na proteção da superfície dos solos dos raios solares durante o período seco, o que permite preservar os organismos vivos presentes. Durante o início do período chuvoso, a energia cinética gerada pelo impacto da água da chuva é minimizada graças à presença das folhas e galhos secos dispostos na superfície. Deste modo, as áreas cobertas por essa fisionomia apresentam menor suscetibilidade aos agentes erosivos. 
Quantoasegundaclassemais representativa, a agropecuária, esta ocupa áreas menores, representando cerca de $29 \%$ da superfície, concentradas principalmente nas porções próximas a montante da bacia. Essas áreas são destinadas a práticas como Agricultura de Sequeiro e criação de bovinos e caprinos. A Agricultura de Sequeiro representa a uma das principais fontes de para pequenos e médios produtores. Dentro desse modelo agrícola, o plantio das espécies é feito durante o início do período chuvoso, com colheita programada para o começo da estação seca. Deste modo, devido às características climáticas da região, os solos nessas áreas passam a maior parte do ano desprotegidos, suscetíveis não só a incidência da radiação solar e erosão eólica, como também as precipitações esporádicas. A criação de animais em algumas áreas também funciona como um agravante devido ao sobrepastejo, que causa compactação dos solos.

Com uma área menor, a agricultura irrigada ocupa cerca de $1 \%$ da superfície total da área. Observa-se que o perímetro se encontra assentado próximo à região jusante da bacia, onde a disponibilidade de água é maior em função da presença do rio São Francisco e as obras estruturais para condução da água do referido rio. Semelhante ao sistema de Sequeiro, o plantio também ocorre durante o período chuvoso, porém, em alguns casos, algumas espécies vegetais são cultivadas o ano inteiro a exemplo da uva, que representa uma das principais fontes de receita da região. O manejo é um dos grandes problemas identificados nessas áreas. Isto porque a utilização gera-se uma hipótese de que os agroquímicos e a utilização de sistemas de irrigação potencializam os processos de degradação dos solos, aumentando o risco desenvolver processos de salinização, o qual irá contribuir na desertificação.

Quanto ao mapeamento das tipologias de solos encontrados na área de estudo, exposto na figura $2 \mathrm{~B}$. Observa-se a presença de 9 classes. Destas, os Argissolos são os mais representativos, ocupando 85,2\% da área de estudo. São solos que abrigam outros grupos como os Argissolos Amarelos e Argissolos Vermelho-Amarelos. São solos que podem variar de moderadamente profundos a profundos, moderadamente drenados a bem drenados, a depender das condições dos ambientes onde se formam.

Por apresentar um horizonte diagnóstico B textural, apresentam concentração maior de argila nas camadas inferiores devido à mobilização e perda do referido elemento na parte superficial. Em ambientes semiáridos, costumam ser menos profundos, onde se verifica também maior pedregosidade nos seus horizontes. Em função das características supracitadas, os Argissolos podem ser considerados suscetíveis aos processos erosivos, principalmente pela diferença no potencial de infiltração nos horizontes superficiais e subsuperficiais. Por outro lado, em condições onde o mesmo apresenta textura menos arenosa e boa permeabilidade a suscetibilidade a degradação é diminuída.

Outras tipologias de solos podem ser identificadas na bacia, porém com representação de menor expressividade. Uma delas corresponde aos Latossolos Amarelos, que ocupam apenas 5,1\% da superfície. Dependendo das condições dos ambientes onde se formam geralmente em áreas úmidas, podem variar de moderadamente profundos a profundos, moderadamente drenados a drenados, apresentando também boa capacidade de retenção de umidade, fator que aumenta a disponibilidade de água para a vegetação. Em regiões onde predomina o clima semiárido, apresentam menor profundidade e presença de material rochoso nas camadas inferiores. As características físicas pontuadas atreladas às unidades de relevo onde ocorrem, geralmente em áreas planas e suavemente onduladas, enquadram esta categoria de solo como de baixa suscetibilidade aos processos de degradação, sobretudo quando protegidos pela vegetação ou quando manejados corretamente. 


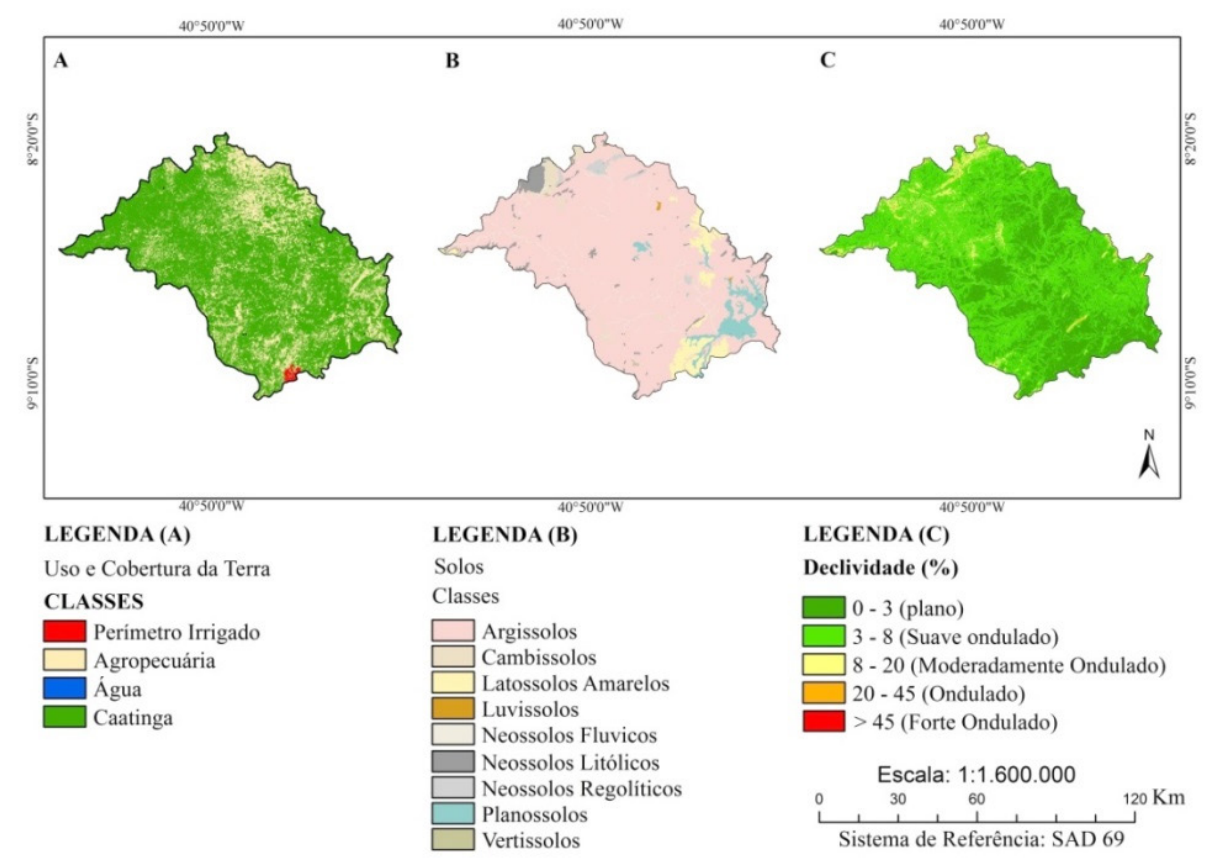

Figura 2. Distribuição espacial das Classes de solos (A), Declividade (B), e uso e cobertura da terra

(C) sub-bacia hidrográfica do rio Pontal, Pernambuco. Fuente: Elaboração própria (2016)

Figure 2. Spatial distribution of soil classes (A), Slope (B), and land use and land cover (C) subbasin of the river Pontal, Pernambuco. Source: Own elaboration (2016)

No mapeamento também são observadas manchas pontuais correspondentes à classe dos Planossolos, localizados na porção a jusante, ocupando $4,2 \%$ da superfície da bacia. São solos que se concentram em áreas planas ou levemente onduladas e geralmente são pouco profundos, sobretudo em regiões de clima semiárido. Seu horizonte superficial varia de arenoso a mediamente arenoso, seguido de um horizonte $\mathrm{B}$ plânico, com textura média, sendo argiloso ou muito argiloso. Por se tratar de um solo bastante coeso, não é comum utilizá-lo para a agricultura, uma vez que o seu horizonte superficial tende a dificultar a penetração das raízes das plantas. Deste modo, as áreas de ocorrência, geralmente, são destinadas à pecuária extensiva.

Outros solos como Neossolos Litólicos, Neossolos Flúvicos e Neossolos Regolíticos são menos expressivos. Somados, ocupam $7 \%$ da área de estudo. Estas classes estão entre os mais suscetíveis aos processos de degradação, sobretudo quando utilizados para fins agropecuários. No estudo desenvolvido por Riberio \& Campos (2010) estes solos, também, foram enquadrados com os maiores riscos a erosão. Segundo Reichert, Amado, Reinert, Rodrigues, \& Suzuki (2016) solos com dificuldades de retenção de água, predomínio de quartzo em sua composição possui maiores risco de erosão.

Outras classes como os Vertissolos, Cambissolos e Luvissolos também estão presentes na bacia, porém somam apenas $0,2 \%$ de toda área de estudo. Deste modo, não interferem nos resultados.

A estrutura geomorfológica da bacia é exposta na figura 2C. Observa-se o 


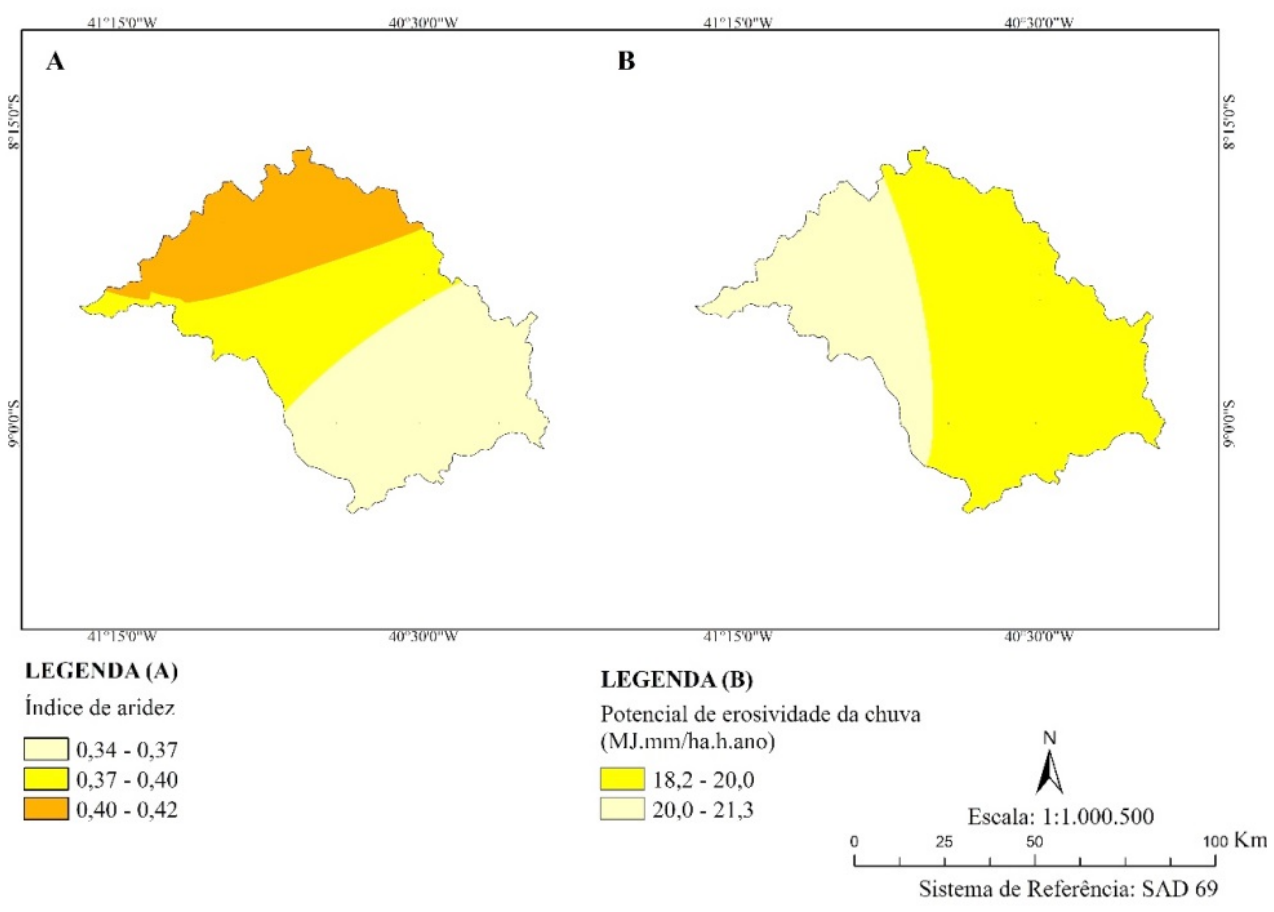

Figura 3. Distribuição espacial para o Índice de aridez (A) e Potencial erosivo da chuva (B) na bacia hidrográfica do rio Pontal. Fuente: Elaboração própria (2016)

Figure 3. Spatial distribution for the aridity index (A) and potential erosion of rain (B) in the basin of river Pontal. Source: Own elaboration (2016)

predomínio das unidades de relevo plano e suave ondulado. A ocorrência dominante dessas duas deve-se ao fato da bacia hidrográfica do rio Pontal está totalmente inserida na unidade geoambiental da Depressão Sertaneja, onde predominam áreas pouco acidentadas. Nessas áreas, a atuação dos agentes erosivos é minimizada, principalmente no que se refere a erosão hídrica, uma vez que a velocidade de escoamento superficial é menor, correndo menor carreamento de sedimentos. Quanto à terceira classe de declividade, relevo moderadamente ondulado, estas estão ligadas a presença dos maciços residuais resultantes do processo de formação do Planalto da Borborema. Essas áreas concentram-se principalmente nas regiões a montante, com pequenas manchas no centro e à Jusante da bacia. O potencial erosivo decorrente do escoamento superficial é maior nessas áreas do que em relação às anteriores.

Asuscetibilidade climática à desertificação é quantificada a partir do índice de aridez e potencial erosivo da chuva, expostos na figura 3A e 3B. Embora observe-se três intervalos para o índice de aridez, de modo geral, toda a bacia do rio Pontal, quanto a esse aspecto, é climaticamente suscetível à desertificação, uma vez que conforme valor observado o clima na região é classificado como semiárido. Os menores valores do referido índice são concentrados na porção à jusante da bacia, local onde se concentra a maior parte da população, assim como os perímetros irrigados.

Quanto ao potencial de erosividade da chuva (figura 2B), os intervalos obtidos 


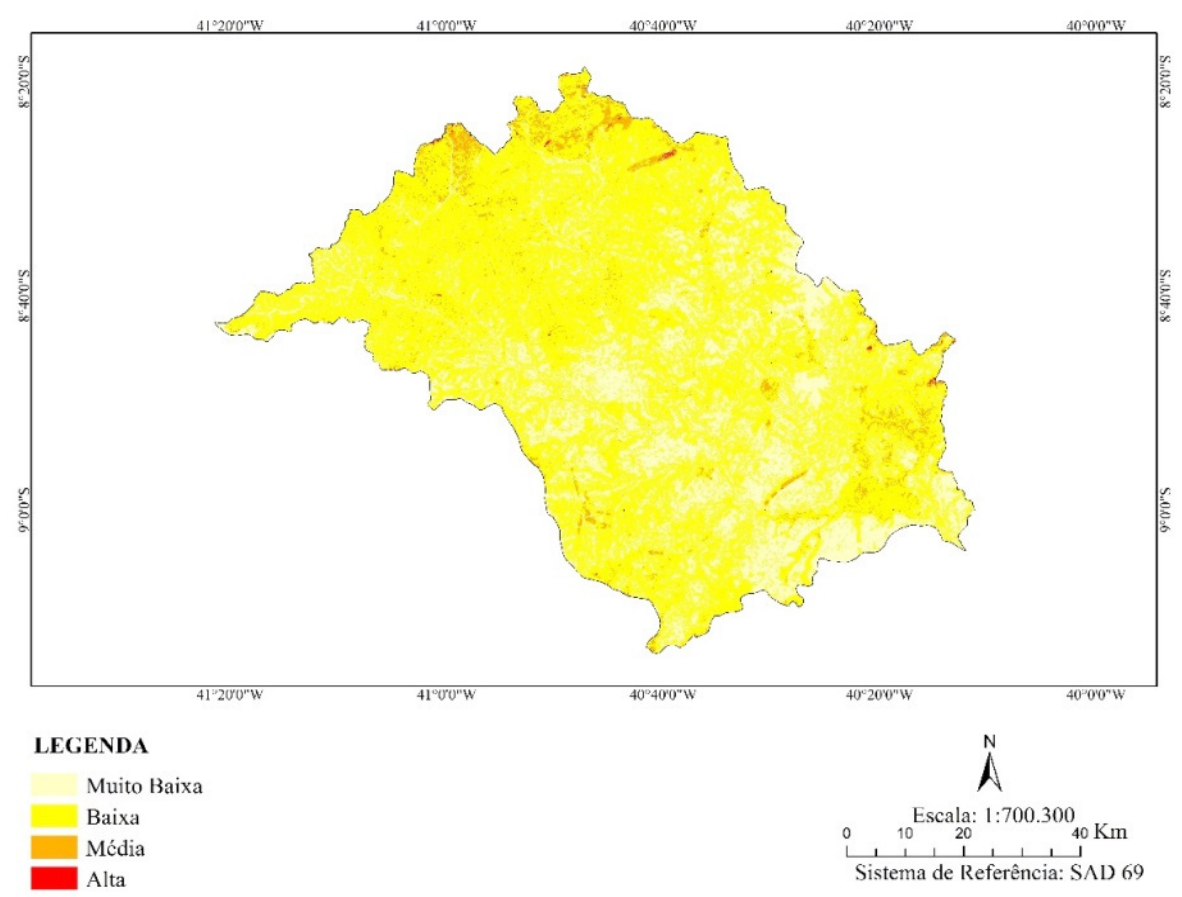

Figura 4. Distribuição espacial das classes referentes às áreas ambientalmente vulneráveis à erosão. Fuente: Elaboração própria (2016)

Figure 4. Spatial distribution of classes related to environmentally vulnerable to erosion areas.

Source: Own elaboration (2016)

indicam que o grau de suscetibilidade é muito baixo. Isto se deve principalmente ao menor potencial pluviométrico da região, visto que os totais de precipitação, historicamente, não costumam superar $400 \mathrm{~mm} /$ ano. Aliado a esta característica, destaca-se também os recorrentes fenômenos de seca que atingem a região, que em casos não raros, costumam durar anos. Segundo Carvalho \& Oyama (2013) e Paredes-Trejoa, Barbosab, \& Kumar (2017), isto se deve principalmente à atuação conjunta de sistemas atmosféricos como o El Niño e Zona de Convergência Intertropical (ZCIT).

O mapeamento referente ao grau de suscetibilidade à erosão dos solos na bacia hidrográfica do rio Pontal pode ser observado na figura 4 . Os atributos empregados para esta estimativa dizem respeito à carta de solos, uso e cobertura da terra e declividade do terreno. Como pode ser observado, predomina a classe de baixa suscetibilidade à erosão (figura 4). Estas ocupam $67,7 \%$ da bacia, com limitações no centro e a jusante. Pesa na configuração deste quadro o baixo potencial erosivo das chuvas na região, atrelada à cobertura da vegetação e maior resistência dos solos (Argissolos e Latossolos Amarelos) aos processos erosivos.

Quanto à segunda classe mais expressiva, Muito Baixa Suscetibilidade, estas se concentram no centro e à jusante, com área de $29,1 \%$. Devem-se principalmente à presença da cobertura vegetal. Outras classes como as de Média Suscetibilidade e Alta Suscetibilidade, concentram-se principalmente na região a montante da 


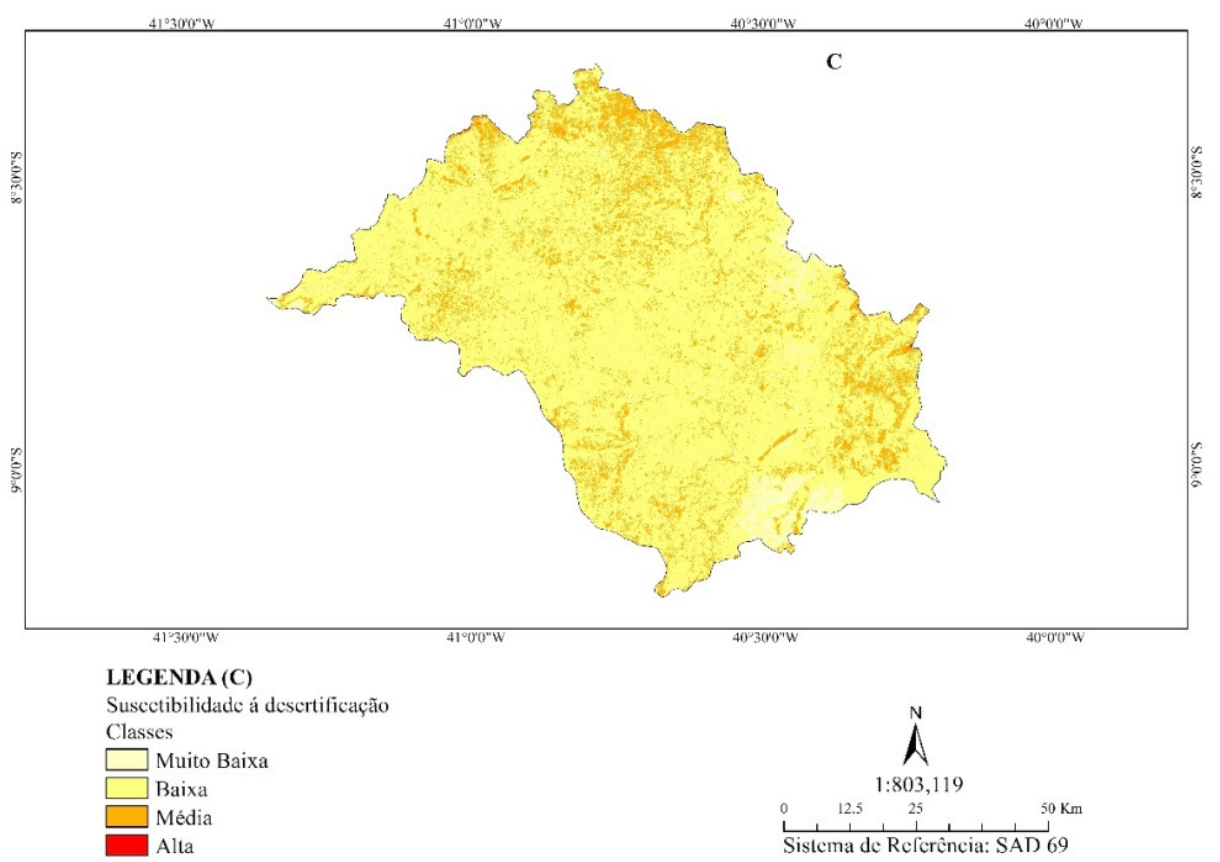

Figura 5. Distribuição espacial das classes de suscetibilidade à desertificação da bacia hidrográfica do rio Pontal. Fuente: Elaboração própria (2016)

Figure 5. Spatial distribution of susceptibility to desertification classes watershed Pontal river.

Source: Own elaboration (2016)

bacia, onde há maior degradação da caatinga e solos menos resistentes. Também estão presentes nessas áreas os maciços residuais, onde a inclinação do terreno é mais acentuada em relação a maior parte da bacia

$\mathrm{Na}$ figura 5 pode ser observado o grau de suscetibilidade à desertificação da bacia hidrográfica do rio Pontal. O mapeamento é resultado do cruzamento dos atributos geoclimáticos anteriormente discutidos. Conforme pode ser observado, há o predomínio da classe de Baixa Suscetibilidade à desertificação (Figura 5). A referida classe ocupa $81,5 \%$ de toda a área de estudo, limitada pontualmente pela presença de outras categorias. Observase que atributos como baixa declividade, solos mais resistentes e cobertura vegetal preservada contribuíram diretamente para a configuração do quadro. No caso da vegetação, este atributo foi praticamente determinante. Observa-se que a segunda maior classe presente na bacia $(15,2 \%)$, que corresponde à de Média Suscetibilidade, pode ser visualizada em várias partes da região, porém, tendem a acompanhar as linhas de desmatamento. Isto fica evidente na porção mais à montante da bacia, onde as áreas convertidas em perímetros agropecuários estão concentradas. Nessas áreas, a atuação dos agentes erosivos é mais intensa, só minimizada pela maior resistência dos solos.

O que foi apresentado e discutido no paragrafo anterior pode ser associado Diéguez et al. (2014). Segundo os autores ao trabalhar com a desertificação uma atenção maior devem ser direcionada a redução da biomassa. Ou seja, quanto maior a redução da cobertura vegetal maiores os riscos à desertificação. 
Outras classes menos expressivas apresentam-se bem concentradas, como é o caso das áreas de Muito Baixa Suscetibilidade à desertificação. Percebese que a mancha mais expressiva se encontra na porção à jusante, justamente onde se encontra o perímetro irrigado de Petrolina. A presença dos Latossolos Amarelos, mais resistentes à degradação, assim como, o baixo potencial erosivo da chuva e menor inclinação do terreno foram determinantes para esta configuração. Outro fator que somado é a presença da vegetação de Caatinga, que se encontra distribuída em volta do perímetro. Estas áreas são mais expressivas que as destinadas à agricultura irrigada.

As áreas de Alta Suscetibilidade foram detectadas na quantificação, porém, não podem ser visualizadas no mapeamento em função da área inexpressiva $(0,01 \%)$.

Os resultados apresentados e discutidos anteriormente segue a mesma dinâmica dos encontrados no estudo de Wijitkosum (2016) na Tailândia. As áreas com maiores severidades e susceptibilidade foram aquelas em que a retirada da cobertura vegetal, paralelas às mudanças na estrutura espacial e localizadas sobre solos com maiores fragilidades a erosão e a salinização foram maiores.

\section{Conclusões}

No geral, a partir do cruzamento de importantes variáveis físico-naturais para identificação de áreas com potencial risco ao desenvolvimento de processos de desertificação, verificou-se que a bacia hidrográfica do Pontal apresenta Baixa suscetibilidade à desertificação. Entretanto, a retirada da cobertura vegetal figura como principal responsável para o aumento do grau de vulnerabilidade.

É importante salientar que este estudo não leva em consideração os indicadores sociais e de produção, variáveis importantes para a identificação de áreas ameaçadas pela degradação das terras.
Devido a grande importância econômica da bacia do Pontal, em função da expansão dos perímetros irrigados, propõe-se que outros estudos sejam desenvolvidos no sentido de encontrar alternativas viáveis para o combate e mitigação dos efeitos da desertificação.

\section{Referências}

Abahussain, A.A., Abdu, A.S., Al-Zubari, W.K., EL-Deen, N.A., \& Abdul-Raheem, M. (2002). Desertification in the Arab Region: analysis of currentstatus and trends. Journal of Arid Environments, 51(2), 521545. https://doi.org/10.1006/jare.2002.0975

Aquino, C.M.S., Oliveira, J.G.S., \& Sales, M.C.L. (2006). Susceptibilidade das terras secas do Piauí: avaliação a partir de índices. Mercator, 5(9), 49-60.

Becerril-Pina, R., Mastachi-Loza, C.A., González-Sosa, E., Díaz-Delgado, C., \& Bâ, K.M. (2015). Assessing desertification risk in the semi-arid highlands of central Mexico. Journal of Arid Environments, 120(8),4-13.https://doi.org/10.1016/j. jaridenv.2015.04.006

Bertoni, J. \& Lombardi, N. F. (1999). Conservação do solo. São Paulo: Ícone.

Bezerra, J.M, Silva, P.C.M.S., Morais, C.T.S.L., \& Batista, R.O. (2011). Utilização de geotecnologias na determinação de áreas susceptíveis à desertificação no Estado do Rio Grande do Norte. Revista Brasileira de Geografia Física, 4(3), 543-561

Carvalho, M.A.V. \& Oyama, M.D. (2013). Variabilidade da largura e intensidade da Zona de Convergência Intertropical atlântica: aspectos observacionais. Revista Brasileira de Meteorologia, 28(3), 305316. 77862013000300007

Crepani, E., Medeiros, J.S., Palmeira, A.F., \& Silva, E.F. (2008). Zoneamento Ecológico- 
Econômico. In T.G. Florenzano (Org.). Geomorfologia: conceitos e tecnologias atuais. (pp. 285-318). São Paulo: Oficina de textos.

D'odorico, P., Bhattachan, A., Davis, K.F., Ravi, S., \& Runya, C.W. (2013). Global desertification: drivers and feedbacks. Advances in Water Resources, 51(9), 326-344. https://doi.org/10.1016/j. advwatres.2012.01.013

Diéguez, E.T., Mancera, G.M., Falcón, A.C., Garibay, A.N., Cepeda, R.D.V., Hernández, J.L.G., \& Amador, B.M. (2014). Análisis de la sequía y desertificación mediante índices de aridez y estimación de la brecha hídrica en Baja California Sur, noroeste de México. Investigaciones Geográficas, Boletín del Instituto de Geografia, UNAM, 85, 6681. https://doi.org/10.14350/rig.32404

Embrapa. (2006). Sistema Brasileiro de Classificação de Solos. Brasília/ Rio de Janeiro: EMBRAPA.

Ferreira, P.S., Gomes, V.P., Santos, A.M., Morais, Y.C.B., Miranda, R.Q., Ferreira, J.M.S., \& Galvíncio, J.D. (2014). Análise do cenário de suscetibilidade à desertificação na bacia hidrográfica do rio Pajeú. Estado de Pernambuco. Scientia Plena, 10(10), 1-11.

Ge, X., Li, Y., Luloff, A.E., Dong, K., \& Xiao, J. (2015). Effect of agricultural economic growth on sandy desertifi cation in Horqin Sandy Land. Ecological Economics, 119(18), 53-63. https://doi. org/10.1016/j.ecolecon.2015.08.006

Granados-Sánchez, D., HernándezGarcía, M. Á., Vázquez-Alarcon, A., \& Ruiz-Puga, P. (2013). Los procesos de desertificación y las regiones áridas. Revista Chapingo serie ciencias forestales $y$ del ambiente, 19(1), 45-66. https://doi. org/10.5154/r.rchscfa.2011.10.077
Hänke, H., Börjeson, L., Hylander, K., \& Enfors-Kautsky, E. (2016). Drought tolerant species dominate as rainfall and tree cover returns in the West African Sahel. Land Use Policy, 59 (2), 111-120. https:// doi.org/10.1016/j.landusepol.2016.08.023

Ibge. (2010). Censo demográfico brasileiro. Instituto Brasileiro de Geografia e Estatística. Rio de Janeiro: IBGE.

Landim, R.B.T.V., Silva, D.F., \& Almeida, H.R.R.C. (2011). Desertificação em Irauçuba (CE): Investigação de Possíveis Causas Climáticas e Antrópicas, Revista Brasileira de Geografia Física, 4(1), 1-21.

Lingbeek, B.J., Higgins, C.L., Muir, J.P., Kattes, D.H., \& Schwertner, T.W. (2017). Arthropod diversity and assemblage structure response to deforestation and desertification in the Sahel of western Senegal. Global Ecology and Conservation, 11(3), 165-176. http:// dx.doi.org/10.1016/j.gecco.2017.06.004

Lucena, D. B., Gomes Filho, M. F., \& Servain, J. (2011). Avaliação do impacto de eventos climáticos extremos nos oceanos pacífico e atlântico sobre a estação chuvosa no nordeste do Brasil. Revista Brasileira de Meteorologia, 26(4), 297-3121.

Mercado-Mancera, G.E., Troyo-Diéguez, A., Aguirre-Gómez, B., Murillo-Amador, M.S., Trasviña Castro, L.F., Beltrán, M., \& García-Hernández, J.L. (2011). Variables edafoclimáticas asociadas a la desertificación. Tropical and subtropical agroecosystem, 13(2), 133-145.

Miranda, E.E. (2005). Brasil em Relevo. Embrapa Monitoramento por Satélite. Campinas: EMBRAPA. Recuperado de http://www.relevobr.cnpm.embrapa.

Paredes-Trejoa, F.J., Barbosab, H.A., \& Kumar, T.V.L. (2017). Validating CHIRPS-based satellite precipitation estimates in Northeast Brazil. Journal of 
Arid Environments, 139(3), 26-40. https:// doi.org/10.1016/j.jaridenv.2016.12.009

Reichert, M., Amado, T.J.C., Reinert, D.J., Rodrigues, M.F., \& Suzuki, L.E.A.S. (2016). Land use effects on subtropical, Sandy soil under sandyzation/desertification processes. Agriculture, Ecosystems and Environment, 233(8), 370-380.https://doi.org/10.1016/j. agee.2016.09.039

Ribeiro, F.L. \& Campos, S. (2010). Vulnerabilidade à erosão do solo da Região do Alto Rio Pardo, Pardinho, SP. Revista Brasileira de Engenharia Agrícola e Ambiental, 11(6), 628-636.

Sampaio, E.P. (2009). Estudio de las prácticas culturales, porosidad del suelo y gestión hídrica en el combate contra la desertificación. Información tecnológica, 20(3), 101-112. http://dx.doi.org/10.4067/ S0718-07642009000300012

Sampaio, E.V.S.B., Sampaio, Y., Vital, T., Araújo, M.S.B, \& Sampaio, G.R. (2003). Desertificação no Brasil: conceitos, núcleos e tecnologias de recuperação e convivência. Recife: Ed. Universitária da UFPE.

Santos, A.M. \& Galvíncio, J.D. (2013). Mudanças climáticas e cenários de suscetibilidade ambiental à desertificação em municípios do estado de Pernambuco. OBSERVATORIUM: Revista Eletrônica de Geografia, 5(13), 66-83.
Santos, M. (2006). Por uma outra globalização: do pensamento único à consciência universal. Rio de Janeiro: Record.

SECTMA. (2009). Programa de Ação Estadual de Pernambuco para o Combate à Desertificação e Mitigação aos Efeitos da Seca. Recife: SECTMA - CEPE.

Souza, B.I., Artigas, R.C., \& Lima, E.R.V. (2015). Caatinga e desertificação. Mercator (Fortaleza), 14(1), 131-150. https://doi. org/10.4215/rm2015.1401.0009

Thornthwaite, C.W. \& Mather, J.R. (1955). The Water Balance. Centerton, N.J.: Drexel Institute of Technology, Laboratory of Technology.

UNCCD. (1994). United Nations Convention to Combat Desertification: Edição Brasileira. Ministério do Meio Ambiente. Brasília.

Wang, Y. \& Yan, X. (2016). Climate change induced by Southern Hemisphere desertification. Physics and Chemistry of the Earth, 5, 1-8. (In press, corrected proof). http://dx.doi.org/10.1016/j.pce.2016.03.009

Wijitkosum, S. (2016). The impact of land use and spatial changes on desertification risk in degraded areas in Thailand. Sustainable Environment Research, 26 (2), 84-92. http:// dx.doi.org/10.1016/j.serj.2015.11.004 